\title{
Foreign bodies in the nose and ear: a review of techniques for removal in the emergency department
}

\author{
P H Davies, J R Benger
}

Patients frequently present to the emergency department for removal of foreign bodies from the nose or ear. Early descriptions of foreign body removal from Roman times include "An insect must first be killed with vinegar and then removed with a probe; the patient should be encouraged to sneeze or better still he should be bound to a table with the affected ear downwards and the table struck with a hammer so that the foreign body may be shaken out of the ear". ${ }^{2}$

Little scientific evidence regarding the best method of foreign body removal exists. The diverse nature of the problem has precluded randomised controlled trails and the medical literature consists mainly of anecdotal case reports. Unfortunately it sometimes seems as if the cavalier attitude to these problems has changed little from those 2000 years ago. The following review attempts to provide a logical, up to date approach to this common complaint.

\section{Methods}

Medline 1966 to August 1998 was searched using the OVID interface and the search terms [ $\{$ exp foreign bodies OR foreign body.mp\} AND \{exp nose OR nose.mp OR exp ear OR ear.mp\}] LIMIT to human and English language. All appropriate articles were retrieved and further searched for relevant references, which were in turn followed up until a complete picture of all previous literature was assembled. These papers were supplemented by information from major ear, nose, and throat (ENT) and emergency medicine textbooks.

\section{Aetiology and epidemiology}

Patients presenting with foreign bodies in the nose or ear are predominantly children in the 2 to 8 age group. ${ }^{2}$ Foreign bodies in the nose are less common than those in the ear and occur almost exclusively in children. The earliest presentation is likely to be around the age of 9 months when a child develops a pincer grip, allowing easy manipulation of small objects. ${ }^{3}$ Patients are more likely to be male and of low socioeconomic status. ${ }^{4}$ Although presentation for removal is generally immediate, in Tong's series of 147 patients, ${ }^{5} 25 \%$ of patients presented after 24 hours. The presence of a foreign body should always be suspected in patients with a chronic unilateral discharge, unexplained pain or suggestive symptoms such as sneezing, snoring or mouth breathing.

One series from India ${ }^{6}$ has shown that insertion of foreign bodies into the ear is associated with pre-existing irritative disease (most commonly chronic otitis externa), although this finding has not been substantiated in other studies. ${ }^{25}$

\section{Animal, vegetable or mineral?}

The range of nasal and aural foreign bodies that present to the emergency department is limited only by the imagination. ${ }^{7}$ A useful classification is animal, vegetable or mineral, ${ }^{8}$ as removal techniques will vary according to the composition of the foreign body. Animals (for example, ants, moths, flies, etc) are the most common foreign bodies in the adult ear and often require immediate attention as they cause pain and agitation in the patient. ${ }^{9}$ They should generally be killed before attempted removal, which then becomes less urgent. Vegetable matter (for example, paper, beans, peas, and cotton buds) tend not only to cause an inflammatory reaction, but also to swell in moist conditions resulting in further impaction and difficulty in removal. The most commonly inserted mineral foreign bodies include beads, rubber erasers, and small toy parts. ${ }^{10}$

\section{Patient preparation}

Writing in the $A B C$ of Otolaryngology, ${ }^{11}$ Ludman states "On initial inspection, the foreign body may be seized and removed with forceps before the child is aware of the result". While this may be true, an unsuccessful attempt significantly jeopardises subsequent efforts. The first attempt is likely to be the most successful, ${ }^{9}$ as repeated tries not only cause further swelling and bleeding but also compromise patient cooperation. ${ }^{12}$ As previously mentioned, children form a large part of this patient group and a careful approach is especially important.

While attitudes are changing there is probably still over-reliance in the emergency department on restraining methods such as papoose strapping boards or "mummy" techniques involving sheets and tape. ${ }^{13}{ }^{14}$ Providing adequate resources are available, sedation in the emergency department may now be a more favoured 
Table 1 Advantages and disadvantages of removal techniques

\begin{tabular}{|c|c|c|c|}
\hline Technique & Orifice & Advantages & Disadvantages \\
\hline Irrigation & Ear & Ease of use & $\begin{array}{l}\text { Contraindicated in tympanic } \\
\text { perforation and for vegetable } \\
\text { matter }\end{array}$ \\
\hline Positive pressure & Nose & Non-traumatic & Risk of barotrauma \\
\hline Negative pressure & Both & $\begin{array}{l}\text { Ease of use } \\
\text { Anterior FBs } \\
\text { Good for small, round FBs }\end{array}$ & $\begin{array}{l}\text { Need solid seal } \\
\text { Posterior FBs difficult } \\
\text { May frighten children }\end{array}$ \\
\hline Glue & Both & $\begin{array}{l}\text { Ease of use } \\
\text { Non-traumatic }\end{array}$ & $\begin{array}{l}\text { FB must be visualised } \\
\text { Adhesion of glue to patient }\end{array}$ \\
\hline Catheter techniques & $\begin{array}{l}\text { Nose/ } \\
\text { both }\end{array}$ & $\begin{array}{l}\text { Good for awkward and } \\
\text { posteriorly placed FBs }\end{array}$ & $\begin{array}{l}\text { Cost and availability of catheter } \\
\text { Possible trauma } \\
\text { Needs good anaesthesia }\end{array}$ \\
\hline $\begin{array}{r}\text { Impression } \\
\text { materials }\end{array}$ & Ear & Ease of use & $\begin{array}{l}\text { Cost and availability } \\
\text { Contraindicated in perforation }\end{array}$ \\
\hline $\begin{array}{l}\text { Surgical } \\
\text { instruments }\end{array}$ & Both & Availability & $\begin{array}{l}\text { Trauma with metal objects } \\
\text { Posterior displacement of FBs }\end{array}$ \\
\hline $\begin{array}{r}\text { Manufactured } \\
\text { instruments }\end{array}$ & Both & $\begin{array}{l}\text { Instrument can be designed } \\
\text { to fit the shape of the FB }\end{array}$ & $\begin{array}{l}\text { Trauma } \\
\text { Posterior displacement of FBs }\end{array}$ \\
\hline
\end{tabular}

${ }^{\star} \mathrm{FB}=$ foreign body.
Table 2 List of recommended equipment for aural and nasal foreign body removal

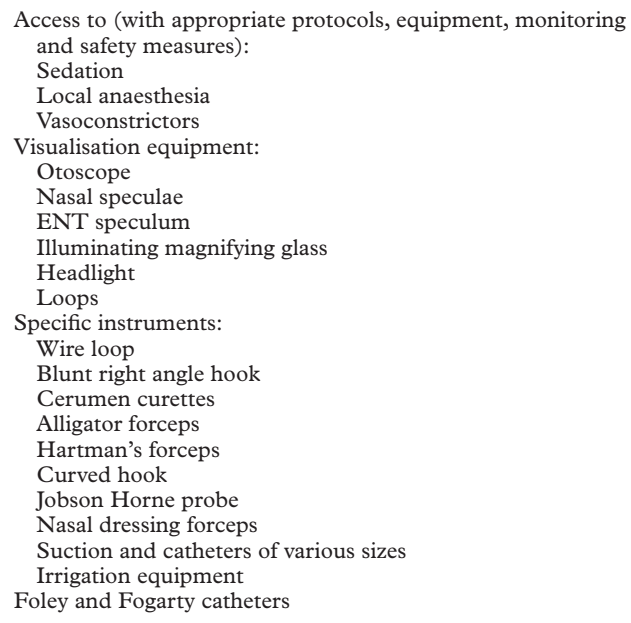

option, although this will not prevent the wriggling caused by a sudden painful stimulus.

\section{Anaesthesia}

Local anaesthesia before foreign body removal is likely to facilitate efficient retrieval. Nasal local anaesthetics are probably best applied using a spray as the foreign body will hamper packing with pledgets. Four per cent lignocaine (lidocaine) is a common choice, although cocaine is a more traditional possibility and is useful for its vasoconstrictor properties. ${ }^{3} \mathrm{Un}$ fortunately the use of cocaine in children is limited by possible toxicity, and in this instance adrenaline (epinephrine) 1:200 000 may be substituted. $^{15}$

Adequate local anaesthesia within the auditory canal is rather harder to achieve. Topically applied local anaesthetic tends to have a partial effect at best, and although a "four quadrant block" has been described, even this may not produce complete anaesthesia, particularly of the tympanic membrane. ${ }^{15}$ Furthermore, four injections of local anaesthetic will do little for compliance in the paediatric population. For this reason a general anaesthetic is to be preferred where the patient is uncooperative or removal of a foreign body proves difficult. ${ }^{16}$

\section{Visualisation}

Adequate visualisation is essential for the successful removal of foreign bodies from the nose and ear. One study has shown that canal lacerations occurred in $48 \%$ of patients where removal was attempted without the use of a microscope, compared with only $4 \%$ where a microscope was used. ${ }^{9}$

The traditional equipment for viewing foreign bodies in the emergency room is the otoscope. Although this provides an adequate light source it is less likely to be of use in retrieval, because of difficult instrumentation through or around the small speculum end. The use of a specialised ENT speculum allows more space for instrumentation. A headlamp or an illuminated magnifying glass probably provide the best form of light source, as they leave both hands free. A pair of magnifying loopes will provide useful hands free magnification. This equipment is not expensive and will prove useful for other practical tasks in the department.

\section{Techniques for removal \\ GENERAL CONSIDERATIONS}

The choice of technique for removal should be related to the exact location, shape, and composition of the foreign body. Removal is rarely an emergency, and the problem can often wait-either for more senior advice or referral to a specialist. The main danger in removing a foreign body from the nose is aspiration, particularly in an uncooperative and crying child who may inhale the object into the airway. ${ }^{17}$ In the ear the risk of drum perforation either before insertion of the foreign body, as a result of its presence or arising from overzealous attempts at removal must always be borne in mind. Finally it is essential to re-inspect the nose or ear after successful removal to ensure that there is not a second foreign body still present. ${ }^{3}$ It is also prudent to check the contralateral orifice, especially in the paediatric population.

The techniques described are summarised in table 1, and their applicability to removal from the nose, ear or both orifices is indicated. Table 2 lists the authors' suggestions for a set of equipment to ease foreign body removal in the emergency department.

IRRIGATION

This technique is useful for a small foreign body close to the tympanic membrane. Irrigation fluid (tap water or normal saline) should be of body temperature to decrease the risk of inner ear stimulation. Perforation of the eardrum or a foreign body composed of vegetable matter, which would swell, are contraindications. ${ }^{9}$ The flow should be brisk and aimed at the superior aspect of the ear canal. ${ }^{15}$ Although specialised irrigation catheters can be used, a butterfly cannula with the needle cut off is soft, flexible, non-traumatic and easily available in the emergency department. ${ }^{4}$ Specialised machines providing a pulsed flow have recently been shown to improve the success rate for removal. ${ }^{18}$

\section{POSITIVE PRESSURE TECHNIQUES}

Various techniques have been proposed for raising the pressure in the upper airway to 
propel the foreign body out of the nostril. All require the opposing (unaffected) nostril to be occluded before the attempt. Parents may have tried nose blowing before attending the department, but further efforts may prove successful, especially if vasoconstrictors are first used to reduce mucosal oedema. ${ }^{15}$ Sneeze induction with pepper ${ }^{1319}$ is now unlikely to meet with the approval of either the parent or the patient!

There have been numerous descriptions of the "magic kiss" or positive pressure technique whereby upper airway pressure is raised, forcing the foreign body through the nostril. ${ }^{20-24}$ This procedure is thought to have been first described by a New York general practitioner, Vladimir Ctibor in the 1960s. ${ }^{25}$ Pressure can be raised either by blowing into the patient's mouth, or by the use of a bag-valve-mask system. ${ }^{26}$ While most of the articles describe a $100 \%$ success rate, it is the authors' experience that this technique is viewed with suspicion by children, even if the parent is blowing, and has provided less impressive results. Although there is a theoretical risk of barotrauma to the tympanic membrane or lower airway, there are no reports of this complication in the literature.

NEGATIVE PRESSURE TECHNIQUES (SUCTION)

This technique is supposedly well suited to round objects that are difficult to grasp with forceps. ${ }^{27}$ Suction is easily available in the emergency department and needs to provide between 100 and $140 \mathrm{~mm} \mathrm{Hg}$ of negative pressure to be of use. ${ }^{28}{ }^{29}$ Commercial suction catheters tend to be metal, increasing the risk of trauma. They can be protected with plastic tips (umbrellas) ${ }^{29}$ or alternatively a soft and flexible endotracheal suction catheter can be used to minimise this risk. ${ }^{15}$ Soft catheters can also be modified with a flanged tip to increase the chance that a smooth, spherical object will be successfully held and withdrawn. ${ }^{30}$ One significant drawback in the paediatric population is fear associated with the noise created by suction devices. The use of play before the procedure may allay a child's fears.

GLUE

The first recorded use of glue was in India in 1977 when a gum based glue was used to retrieve a foreign body. ${ }^{31}$ This has been superseded by faster setting cyanoacrylate "superglues" and is now in common use. ${ }^{32-34}$ It is most effective in removing smooth, round objects that are difficult to grasp. The foreign body must be dry and easily visualised so that the risk of accidental contact with the mucosa or tympanic membrane is avoided. Care needs to be taken to limit the amount of glue introduced into the ear. Although patient compliance is required the technique has been found to be generally acceptable to children.

CATHETER TECHNIQUES

Both Foley ${ }^{35}$ and Fogarty ${ }^{36-38}$ balloon catheters have be used to remove foreign bodies. The technique entails sliding an uninflated balloon past the foreign body and then inflating the balloon before pulling back on the catheter.
Described for use in both the nose and ear this method seems to have found most favour in nasal foreign body removal. It is useful when the foreign body is posteriorly placed, and not amenable to instrumental removal. The application of a local anaesthetic and vasoconstrictor agent is generally required. Balloon catheters may also be used to prevent posterior migration of a foreign body while other methods of removal are used.

IMPRESSION MATERIALS

This method was first described in 1977 by Stassen and Hilding but has since had little publicity. ${ }^{39}$ Semiliquid materials such as acrylic, dental alginate, and silicone were poured into the external meatus encompassing the foreign body and allowed to set. Foreign body and impression material were then both removed. A success rate of $92 \%$ was reported in cases that had been referred from the emergency department. Problems were found relating to the length of drying time, but it would appear that the materials were well tolerated. Perforation of the ear drum is a contraindication to this technique.

SURGICAL INSTRUMENTS

Many surgical instruments have been designed or adapted to assist in the removal of foreign bodies. $^{40}{ }^{41}$ Their use is commonly associated with abrasions and bleeding, ${ }^{9}$ and more rarely with perforation of the tympanic membrane. This technique should therefore only be attempted under direct vision in a compliant patient. The choice of instrument depends on the type of foreign body. Alligator or other forceps are useful for irregular objects with an easily visible edge that can be grasped. Hooks, curettes and loops are required when the foreign body is smooth or spherical and impossible to grasp. In the nose, insertion along the nasal floor or side of the nasal septum allows positioning behind the foreign body before removal by traction. These techniques are of little value with friable foreign bodies, which tend to tear on removal.

MANUFACTURED INSTRUMENTS

A number of instruments manufactured from various pieces of equipment have been described in the literature, though these generally mimic equipment already in service. The paper clip seems a popular item, from which is fashioned a wire loop or hook to assist in retrieval. ${ }^{42}$ If using this method, care should again be taken to ensure that there is minimal trauma to the patient.

UNIQUE TO THE TYPE OF FOREIGN BODY

The ingenious suggestion of using a magnet for removal of ferrous items ${ }^{44}{ }^{45}$ has not yet been supported by case reports. The expense of buying one that is of sufficient strength for removal, combined with the relative lack of use, is likely to limit this method of retrieval.

The fortuitous discovery that ethyl chloride dissolves Styrofoam beads ${ }^{46}$ provides another unique approach to the removal of a common foreign body. 
INSECT DROWNING

Live animal foreign bodies in the ear are extremely distressing to the patient and should be killed before removal. This is best achieved by filling the ear canal with a liquid such as olive oil, methylated spirit, or lignocaine. ${ }^{815}$ Removal then becomes an urgent rather than an emergent procedure. Lignocaine also appears to have a more specific irritant effect that drives insects, specifically cockroaches, from the ear canal. ${ }^{47}$

COMPLICATIONS AND REFERRAL

Complications may arise from the foreign body itself, the examination or attempted removal (by physician or patient). Reported complications include abrasions, bleeding, infection, aspiration, and perforation of the tympanic membrane. ${ }^{15}$ The latter is rare but if suspected the patient should be referred for further assessment. Failure to remove a foreign body also necessitates non-urgent referral unless the patient is in pain or is at risk of aspiration. Caustic foreign bodies such as batteries can cause mucosal damage including ulceration and necrosis, and these cases should be referred urgently. ${ }^{48}$

FOLLOW UP

No routine follow up is required, except in cases of infection, severe trauma, or perforation of the ear drum. It is important to check the other aural and nasal orifices before discharge to exclude coexisting foreign body. Parents should be educated to minimise the exposure of children to potential foreign bodies. ${ }^{27}$

\section{Summary}

Removal of foreign bodies from the ear or nose is a common problem and can be either a frustrating or gratifying procedure, depending on outcome. Previous experience and common sense are likely to influence the physician's choice of method, as is the availability of retrieval equipment. Current evidence shows that this practice is likely to lead to a high failure and complication rate.

Education of junior doctors is the best way to increase retrieval rates in the emergency department. Both authors have successfully incorporated a five minute review of this topic into departmental teaching programmes on ENT emergencies. The information from these talks has been reinforced by the creation of a foreign body removal pack, accompanied by a summary card of available retrieval methods.

It is inevitable that some patients will need to be referred to an ENT specialist and local policy will dictate referral routes. A realisation that difficult patient groups, such as children, should be referred without an attempt in the emergency department is likely to limit complication rates.

Conflict of interest: none.

Funding: none.

1 Weir N. Otolaryngology-an illustrated history. Oxford: Butterworths, 1990

2 Baker MD. Foreign bodies of the ears and nose in childhood. Pediatr Emerg Care 1987;3:67-70.
3 Rosen P, Barkin R. Emergency medicine-concepts and clinical practice, 4th Ed. St Louis: Mosby, 1998.

4 Fritz S, Kelen GD, Siverton KT. Foreign bodies of the external auditory canal. Emerg Med Clin North Am 1987;5: 83-91.

5 Tong MCF, Ying SY, van Hasselt CA. Nasal foreign bodies in children. Int $\mathcal{F}$ Pediatr Otorhinolaryngol 1996;35:207-11.

6 Das SK. Aetiological evaluation of foreign bodies in the ear and nose. F Laryngolog Otol 1984;98:989-91.

7 Malhotra C, Arora MML, Mehra YN. An unusual foreign body in the nose. F Laryngol Otol 1970;84:539-40.

8 Bear VD. The ear-'dos and don'ts'. Med f Aust 1991;154: $603-5$.

Bressler K, Shelton C. Ear foreign body removal: a review of 98 consecutive cases. Larygoscope 1993;103:367-70.

10 Sharma S, Mehra Y, Panda N. Foreign body in the ear and upper aerodigestive tract. Indian f Pediatr 1992;59:347-55. upper aerodigestive tract. Indian f Pediatr 1992;59:347-55.
Ludman H. Injuries and foreign bodies. ABC of otolaryngology. 4th Ed. London: BMJ Publishing Group, 1996.

ogy. 4th Ed. London- BMown's otolaryngology. 5th Ed. Oxford:
Ransome J. In: Scott-Brow Butterworths, 1992

13 Brownstein DR, Hodge D. Foreign bodies of the eye, ear and nose. Pediatr Emerg Care 1988;4:215-18.

14 Pfaff JA, Moore GP. Eye, ear, nose and throat-pearls, pitfalls and updates. Emerg Med Clin North Am 1997;15:327-40.

15 Votey S, Dudley JP. Emergency ear, nose and throat procedures. Emerg Med Clin North Am 1989;7:117-54.

16 O'Donoghue GM, Bates G, Narula AA. Clinical ENT-an illustrated textbook. Oxford: Oxford University Press, 1992.

17 Werman H. Removal of foreign bodies of the nose. Emerg Med Clin North Am 1987:5:253-63.

18 Jones I, Moulton C. Use of an electric syringe in the emergency department. F Accid Emerg Med 1998:15;327-8.

19 Maran AGD, Stell PM. Clinical otolaryngology. Oxford: Blackwell Scientific, 1979.

20 Hore CT. Nasal foreign body removal in children. Med $\mathcal{f}$ Aust 1996;164:448.

21 Backlin SA. Positive pressure technique for nasal foreign body removal in children. Ann Emerg Med 1995;25:554-5. 2 Meadoff TM. Nasal foreign body removal. Ann Emerg Med 1995;26:390

23 Fallis GB, Ferguson K, Waldman M. Simple technique for removing foreign objects from the nose. Am Fam Physican 1992;46:1046-7.

24 Scolinik D. A 'new' manoeuvre for removing foreign bodies from the nose. Arch Dis Child 1988;63:226.

25 Guazzo E. Removal of foreign bodies from the nose. N Engl f Med 185;312:725.

26 Cohen HA, Goldberg E, Horev Z. Removal of nasal foreign bodies in children. Clin Pediatr 1993;32:192.

27 Foster DL. Suction removal of foreign bodies (letter). Pediatr Emerg Care 1989;5:73.

8 D'Cruz O, Lakshman R. A solution for the foreign body in the nose problem. Pediatrics 1998; 81:174.

29 Kadish HA, Corneli HM. Removal of nasal foreign bodies in the pediatric population. Am f Emerg Med 1997;15:54-6.

0 Morris MS. New device for foreign body removal. Laryngoscope 1984;94:980.

31 Zeinulabdeen $M$. New touch and pull method to remove foreign bodies from the ear. F Indian Med Assoc 1977;68: $97-8$.

32 Hanson RM, Stephens M. Cyanoacrylate assisted foreign body removal from the ear and nose in children. Pediatric Child Health 1994;30:77-8.

33 Pride H, Schwab R. A new technique for removing foreign bodies of the external auditory canal. Pediatr Emerg Care 1989;5:135-6.

34 Thompson MP. Removing objects from the external auditory canal. $N$ Engl f Med 1984;311:1635.

35 Henry LN, Chamberlin JW. Removal of foreign bodies from oesophagus and nose with the use of a Foley catheter. Surgery 1972;71:918-21.

36 Nandapalan V, McIlwain JC. Removal of nasal foreign bodes with a Fogarty biliary balloon catheter. 7 Laryngol Otol 1994;108:758-60.

37 Fox JR. Fogarty catheter removal of nasal foreign bodies. Ann Emerg Med 1980;9:37-8.

38 Virnig RP. Nontraumatic removal of foreign bodies. Minn Med 1972;55:1123.

39 Raz S. Impression materials for removal of aural foreign bodies. Ann Otol 1977;86:396-9.

40 Chalfin L. Tricks of the trade- out of the nose. Emergency Medicine 1986;18:96.

41 McMaster WC. Removal of foreign body from the nose. FAMA 1970;213:1905.

42 Hendrick JG. Another solution for the foreign body in the nose problem. Pediatrics 1998;82:395.

43 Wavde V. Removal of foreign body from nose or ear. Aust Fam Physician 1988;17:904.

44 Stool SE, McConnel CS. Foregn bodies in pediatric otolaryngology. Clin Pediatr 1973;12:113-16.

45 Gray RF, Hawthorne M. Synopsis of otolaryngology. 5th Ed. Oxford: Butterworth Heinemann, 1992.

46 Brunskill AJ, Satterthwaite BSN. Foreign bodies. Ann Emerg Med 1994;24:757.

47 O'Toole K, Paris PM, Stewart RD. Removing coakroaches from the auditory canal. N Engl f Med 1984;312:1197.

48 Rachlin LS. Assult with battery. N Engl f Med 1984;311: 921-2.

49 Tong MCF, Van Hasselt CA, Woo JKS. The hazards of button batteries in the nose. F Otolaryngol 1992;21:458-60 